\title{
Relating carbon and energy intensity of best-performing retailers with policy, strategy and building practice
}

\author{
Ana Ferreira (D) - Manuel Duarte Pinheiro • \\ Jorge de Brito • Ricardo Mateus
}

Received: 17 October 2018 / Accepted: 10 January 2020

(C) Springer Nature B.V. 2020

\begin{abstract}
Retail stores are amongst the building typologies with the highest carbon (CI) and energy intensities (EI). However, previous studies have only explored best practice EI of food and non-food retailers, without identifying best practice CI threshold values. This paper presents a five-step analysis of CI and EI amongst the highest revenue retailers, benchmarking best and worst performing CI and EI retailers, analysing their nationality, performing a content analysis on their CSR reports and comparing results in terms of differentiation policies, strategies and building practices that can lead to increased environmental performance. Combined CI and EI best practice threshold values were found simultaneously under $346 \mathrm{kWh} / \mathrm{m}^{2} / \mathrm{y}$ and $115 \mathrm{~kg} \mathrm{CO} 2 \mathrm{eq} / \mathrm{m}^{2} / \mathrm{y}$ for food retailers and under $146 \mathrm{kWh} / \mathrm{m}^{2} / \mathrm{y}$ and $70 \mathrm{~kg}$ $\mathrm{CO}_{2} \mathrm{eq} / \mathrm{m}^{2} / \mathrm{y}$ for non-food retailers. In terms of policy, best-performing retailers shared a strong top-down management commitment towards sustainability across all
\end{abstract}

A. Ferreira $(\varangle) \cdot$ M. D. Pinheiro $\cdot$ J. de Brito

CERIS, Instituto Superior Técnico, Universidade de Lisboa, Av. Rovisco Pais, 1, 1049-001 Lisbon, Portugal

e-mail: anaferreiraleonardo@tecnico.ulisboa.pt

M. D. Pinheiro

e-mail: manuel.pinheiro@tecnico.ulisboa.pt

J. de Brito

e-mail: jb@civil.ist.utl.pt

R. Mateus

Department of Civil Engineering, CTAC, University of Minho,

Campus de Azurém, 4800-058 Guimarães, Portugal

e-mail: ricardomateus@ civil.uminho.pt business areas $(p=0.04)$ and an increased use of referential reporting standards, particularly of GRI standards $(p=0.05)$ and of the GHG protocol $(p=0.01)$. In terms of strategy, they established ambitious energy goals, such becoming $100 \%$ supplied by renewable energy $(p=0.05)$ or carbon neutral by 2020. As for building practice, LED and photovoltaic technology were the most popular high-performance solutions, but only the use of natural refrigerants $(p=0.001)$ and gas transfer to $\mathrm{CO}_{2}(p=0.0007)$ were related to best-performing practice. The variability of CI and EI found in this study shows that it is already possible to reduce the retail sector's contribution to global GHG emissions considerably. The proposed best practice CI and EI reference levels, linked to corporate policy, strategy and building practice, are useful new tools for retail energy-management, which can further promote sustainability in retail buildings, thus allowing a deeper understanding of how to decarbonize the retail building sector.

Keywords Food and non-food retailers · Energy intensity . Carbon intensity . Corporate policy - Energy strategy $\cdot$ Best practice

\section{Introduction}

The building sector is responsible for about $40 \%$ of the total energy consumption and $36 \%$ of $\mathrm{CO}_{2}$ emissions in Europe; out of these, the contribution of retail stores in the total $\mathrm{CO}_{2}$ emissions of the building stock is about 9\% (Building Performance Institute Europe 2011). 
Additionally, retail stores have one of the highest energy intensities (EI) - 500 to $1.000 \mathrm{kWh} / \mathrm{m}^{2} / \mathrm{y}$ - especially when refrigeration systems are used (Schönberger et al. 2013). Likewise, retailers' carbon intensity (CI) is quite high in terms of direct greenhouse gas (GHG) emissions and even higher in terms of indirect GHG emissions - a factor of 7 for its supply chain and a factor of 3 for its products' end life. Retailers' overall carbon footprint is thus a substantial problem requiring a comprehensive sustainability-driven management solution (ENDS Carbon-University of Edinburgh Business School 2009).

The retail sector controls and acts as the gatekeeper for goods and services consumers are offered and, as such, it can influence behaviour and consumption patterns (The Conservation Foundation of Greater Toronto 2006). Because of its broad reach, the retail sector has the potential to affect society in a way that not many other industries can. Corporately, retailers can define environmentally oriented policies for themselves and for suppliers, and at the store level, they can showcase sustainable built stores and educate consumers. The retail sector is also in a key position in the construction industry as it can influence the supply stream of materials and technologies used in this sector (U.S. Department of Energy 2008). For instance, the energy policies of large purchasers of energy efficient equipment, such as the retailers, can push the market towards the development of more efficient equipment. Likewise, vendors also try to move their customers up the valuechain and sell better quality, energy-efficient equipment. As retail is a highly concentrated industry in terms of ownership and sales (The Conservation Foundation of Greater Toronto 2006), there is an easier best practice communication across all players in the industry. The similarities between companies make lessons learned from best-performing retailers easily transferred to competitors or other commercial units.

International regulation is also pushing retailers into energy and carbon efficiency, namely due to the Paris Agreement (United Nations 2015) or the Energy Performance of Buildings Directive (EPBD) (European Parliament 2018). In fact, according to the EPBD, commercial buildings need to become $70-80 \%$ more energy-efficient, and all new buildings must be nearly zero energy buildings (nZEBs) by 2020. nZEB is a building that has a very high energy performance and where the nearly zero or very low amount of energy required should to a very significant extent be covered by energy from renewable sources, including renewable energy produced on-site or nearby (European Union 2016). A management culture based both on legal requirements and voluntary obligations is transversal for retailers. Therefore, what sets best-performing retailers apart from the others should be based on higher levels of ambition in terms of energy strategy and internalization of sustainability principles across all business areas, leading to different results in terms of environmental performance. Likewise, the consistency with which high-performance sustainable building solutions are used across retailers' property portfolio is reflected in lower EI and CI and using them sporadically will fail in terms of achieving the best environmental performance. Hence, a holistic approach based on the role of corporate culture and social responsibility play in achieving low CI and EI is suggested here as a key to mitigating climate change impacts related to the retail industry effectively.

Previous studies identified best practices to promote energy-efficiency in food and non-food retail stores (Galvez-Martos et al. 2013; Schönberger et al. 2013; Tassou et al. 2011), as well as carbon savings, mostly from an energy efficiency viewpoint (Fieldson and Rai 2009; Jenkins 2008; Jiang and Keith Tovey 2009; Spyrou et al. 2014). Other studies assessed corporate barriers and drivers for energy and carbon efficiency (Christina et al. 2015; Dixon-O'Mara and Ryan 2018; Sullivan and Gouldson 2013). Also, other studies have focused on policy and strategy challenges to address climate change with regard to the building stock (Carballo-Penela and Castromán-Diz 2015; Sebi et al. 2019). However, the current knowledge about what constitutes best practice amongst retailers in terms of policy, strategy and building practice to reduce EI, but more particularly CI, as well as what differentiates "best-performing" from conventional retailers (e.g. retailers with best practice $\mathrm{CI}$ and $\mathrm{EI}$ within the sector) is extremely limited. Thus, it is necessary to hypothesise about what best practice thresholds for retailers could be in terms of EI and CI, and what differentiating corporate policies, strategies and building practices contribute most to best-performing retailers' increased environmental performance.

This study is innovative by relating best practice CI and EI and best-performing retailers' policy, strategy and building practice. Two specific questions were tested in the present study: (i) What can be considered as best practice CI and EI within the retail sector? and (ii) What is the policy, strategy and building practice of the best-performing retailers that leads to a better 
environmental performance? In order to answer these questions, we define our understanding of policy, strategy and energy-related building practice for the present study (each of these key-concepts represents an own body of research, which out of the scope of the present paper to analyse).

Policies are formal rules of an organization that help standardize decision-making. Policy can be defined as a plan of what to do that has been agreed to officially by a business organization or a government. The political context for retailer's climate change action has been set mainly by the Paris Agreement (which provided an international framework for climate change policy, centred on the premise of holding the increase in the global average temperature to well below $2{ }^{\circ} \mathrm{C}$ above pre-industrial levels and pursuing efforts to limit the temperature increase to $1.5{ }^{\circ} \mathrm{C}$ above pre-industrial levels), by the Montreal Protocol (which set to phaseout hydrofluorocarbon emissions by 2036) and at the European level, by the EPBD and the Energy Efficiency Directive (European Parliament 2018), promoting the improvement of the energy performance of buildings. Nonstate actors, especially those with an important carbon footprint like corporate retail, can contribute significantly to countries' ability to mitigate emissions by pursuing ambitious climate action. By peaking and reducing emissions as soon as possible and by operating energy-efficient buildings with natural refrigerants, retailers can help to meet the government's decarbonising goals and avoid the worst impacts of climate change (Levin and Rich 2017).

In parallel, strategy requires a comprehensive plan, made to accomplish the organizational goals. It is a game plan, chosen to achieve the organisational objectives, gain the trust of customers, attain competitive advantage and acquire a better market position. In particular, environmental proactive management practices are commonly associated with benefits such as waste minimization, reducing environmental risks, energy use and material needs (Carballo-Penela and Castromán-Diz 2015).

Additionally, practice is the organised way in which an individual or a group carries out a particular activity. Building practice refers to the building solutions chosen by retailers to achieve energy strategy goals whereas best practice refers to a method or technique that has been generally accepted as superior to any alternatives because it produces results that are superior to those achieved by other means (Galvez-Martos et al. 2013).
CI and EI best practice reference levels for both food and non-food retailers were presented here as benchmarking tools for more efficient carbon and energy corporate management. The carbon footprint of retail stores can be minimized either by reducing EI or CI (or both); hence, these two parameters are analysed simultaneously. According to our study, achieving best practice reference levels across the retail industry would allow reducing EI by $50 \%$ and CI by $60 \%$, which represents a significant potential for improving the energy performance in retail buildings. The present best practice $\mathrm{CI}$ and EI reference levels empower decisionmakers to rank their stores in terms of energy and carbon efficiency, providing at the same time targets for energy and carbon management. Differentiating policies, strategies and building practice like those presented here are also expected to support retailers' decision-making process to increase the environmental performance.

\section{Materials and methods}

A qualitative comparison was performed regarding best and worst practice retailers in terms of policy, startegy and building practice, ranked according to their carbon intensity (CI) and energy intensity (EI). Five main steps were considered for this analysis.

In step 1 (CI and EI benchmarking), the context for EI and CI ranking was formulated, following the methodology of Ferreira et al. (2018a, 2018b). Here, the EI and CI of the stores of the 250 highest revenue retailers were analysed based on publicly available data from the fiscal year 2016 (Deloitte and Stores Media 2016), to establish best practice reference levels for these two variables. Outliers were identified with the interquartile range and removed as to reduce error in the dataset. CI was expressed as the total kilogramme emissions of carbon-dioxide equivalent per unit of $\mathrm{m}^{2}$ of gross floor sales area per year $\left(\mathrm{kg} \mathrm{CO}_{2} \mathrm{eq} / \mathrm{m}^{2} / \mathrm{y}\right)$, according to the GHG Protocol methodology for scopes 1 (all direct GHG emissions including stationary combustion for comfort heating and fugitive emissions from refrigerant systems) and scope 2 (all indirect GHG emissions from the consumption of purchased electricity, heat or steam) (WRI and WBCSD 2016). EI was expressed as the total final energy consumption in $\mathrm{kWh}$ per unit of $\mathrm{m}^{2}$ of gross floor sales area per year $\left(\mathrm{kWh} / \mathrm{m}^{2} / \mathrm{y}\right)$. The initial 250 retailers' sample was reduced to those retailers that presented EI or CI data (39\% of the initial sample). Even 
though some retailers had a mixed typology of store formats in their business portfolio, they were characterized as food or non-food retailers according to the predominant number of stores in each format. In addition, retailers were analysed into food or non-food categories, because of the significant EI/CI differences caused by refrigeration systems. The energy consumption profile of food retailers was characterised by a high demand of electricity for refrigeration, which included hypermarkets, supermarkets, discount stores, convenience stores and cash \& carry stores (Galvez-Martos et al. 2013). The non-food category included primarily home improvement stores, drug stores/pharmacies, department stores, furniture/decoration stores, household appliances/electronics stores, auto-shops and office supplies stores. CI data were collected from 37 food retailers (which provided 39 entries) and from 35 nonfood retailers (which provided 38 entries), and EI data were collected from 34 food retailers (which provided 56 entries for EI) and from 25 non-food retailers (which provided 35 entries for EI). The term "entries" refers to aggregated EI or CI data for either a retailer's overall performance, or for a retailers' brand or country of operation. EI and CI data were published in Data in Brief article (Ferreira et al. 2018a, 2018b). CI was reported less frequently by retailers than EI (particularly for non-food retailers); hence, the different counts between CI and EI. Each retailer of the analysed sample presented aggregated data for an average 3.120 stores and 5.5 million $\mathrm{m}^{2}$ of total sales area. The fact that the analysed retailers operate in all major markets (USA, Eurozone, UK, Japan and other emerging markets), have a revenue of at least 3 billion US\$ and employ on average over 100.000 workers each are also indicators of the representativeness of the sample. In addition, most screened retailers (90\%) followed the Global Reporting Initiative (GRI) standards or resorted to third-party certifications to validate their EI and CI data.

The benchmarking of retailers' EI and CI was used as a tool for comparing environmental performance and identifying improvement opportunities (Stapenhurst 2009). Fundamentally, the value of benchmark stands in comparing one's business processes and performance metrics to industry's best practices, in the quest for increased performance (Wireman 2004). As no official definition of best practice benchmarks existed within the retail sector (Galvez-Martos et al. 2013), the methodology proposed by Ferreira et al. (2018a, 2018b) to set best performance benchmarks is based on previous works developed for other sectors (de Fátima Castro et al. 2015) and defined the threshold of the $25 \%$ bestperforming retailers within the sector, as the best practice both for EI and CI. Hence, best-performing food and non-food retailers were identified applying the mathematical operation first quartile (Q1), which set them at the upper limit of the first quartile, equivalent to the boundary of the $25 \%$ lowest values. Based on the same methodology, the mathematical operation fourth quartile (Q4) was used to define the benchmark for the worst performing food and non-food retailers, which has been set at the upper limit of the fourth quartile, equivalent to the boundary of the $75 \%$ highest values.

In step 2 (desk research) and for each identified best and worst performing retailers, policy, strategy and building practice data were searched by the authors online, mainly in sustainability or CSR reports. Only the most recent (dating from 2016) and available sustainability/CSR retailers' reports were considered as to compare the most updated data. To ensure permanent access to the data that support the presented results, all internet references cited in our study were compiled in a data repository (Ferreira (2018) in the References).

In step 3 (data screening and organization), data were organized in different tables for food retailers and one for non-food retailers, according to the variables policy, strategy and building practice. Two sample strategies were selected: maximum variation sampling and deviant case sampling (Suri 2011). Data organization was made the following way: CSR/sustainability reports were searched for recurring themes, which were recorded under each variable's table, to identify core consistencies and meanings (i.e. patterns) (Miles and Huberman 1994; Patton 2002). These patterns were then sorted into categories, according to internal heterogeneity (the extent to which the data belonging in a certain category hold together) and external heterogeneity (the extent to which differences in amongst categories are clear). They were also validated by all authors to be reasonably inclusive of the analysed data as to cover our research questions. Hence, for each variable, data were organized according to the most general category that could embrace each of the identified listed measures. Only measures that were referenced by more than $10 \%$ of best-performing retailers were included in the presented tables. In total, 31 best-performing retailers were analysed (18 food retailers and 13 non-food retailers) against 27 worst performing retailers (17 food retailers and 10 non-food retailers). Nevertheless, the original grids used to code all data were compiled in a data repository 
(Santos Ferreira (2019) in References). The data retrieved for the variable "policy" was organized in Table 2 under the categories: "CSR Principles and Policy", "United Nations' Partnerships", "Sustainability Indexes", "Certification Systems" and "Reporting Standards". The data retrieved for the variable "strategy", was organized in Table 3 under the categories: "Goal setting and reporting", "Support management's systems" and "Green building". The data retrieved for the variable "building practice", data were organized in Table 4 under the categories: "Envelope", "HVAC systems", "Refrigeration systems", "Lighting", "Renewable energy sources" and "Water management".

In step 4 (nationality analysis), the nationality analysis of the sampled retailers was performed, as to infer the impact of local culture in each analysed variable (policy, strategy and building practice). The geographical provenance of the sampled retailers was attributed according to their country of origin, despite the fact that most of the analysed retailers operate stores in more than one country. Hence, most of the analysed retailers were European (48\%), followed by North American (33\%) and Asian (10\%). The remaining analysed retailers were African (4\%) Australian (2\%) and South American (2\%)

(Fig. 1). Within Europe, $28 \%$ of retailers were from
Germany (7\%), France (8\%) and the UK (13\%), whereas in North America $28 \%$ of retailers were from the USA

In step 5 (data analysis), a detailed content analysis of the information presented in best practice and worst practice retailers' sustainability/CSR reports was conducted, according to the variables "policy", "strategy" and "building practice" and following the methodology of Sullivan and Gouldson (2013). Data was searched for divergence in terms of deviant cases that did not fit the dominant identified patterns (included in Santos Ferreira (2019)), as well as rival explanations for the results (Miles and Huberman 1994; Patton 2002). To increase the rigour of data analysis, the authors have resorted to the triangulation technique, checking for their consistency with other authors' theories and data sources (see the "Discussion" section). A comparison analysis was carried out between best and worst performing retailers, based on the percentage of retailers that cited each of the listed categories' measures in their sustainability/CSR reports, in order to identify differentiating measures from best-performing retailers responsible for a higher environmental performance. In addition, the statistical test chi-square $(\chi 2)$ for homogeneity of population was carried out between best and worst performing retailers, to rule out the null hypothesis (where $p<0.05$ confirms

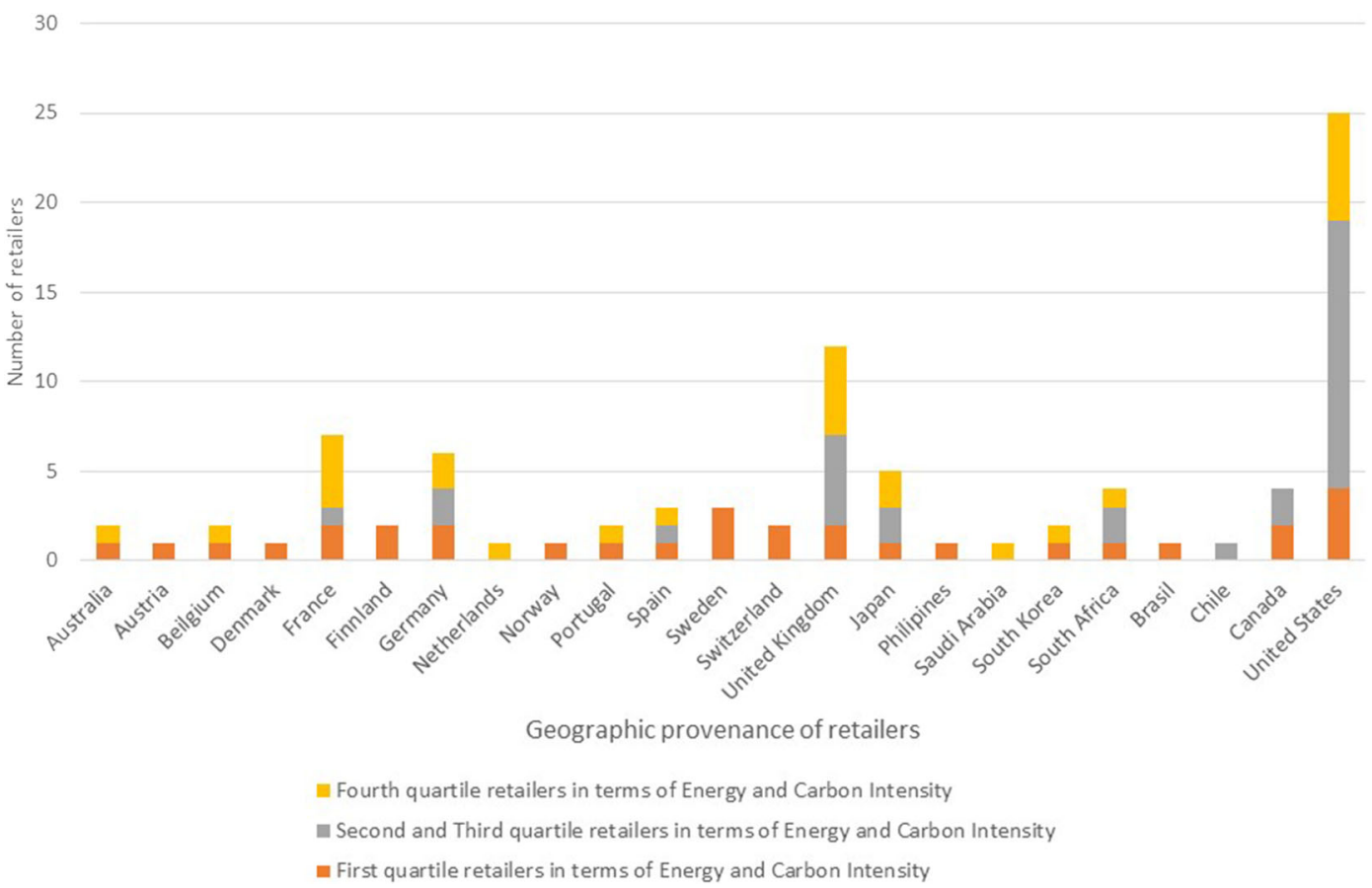

Fig. 1 Distribution of food/non-food retailers according to geographic provenance, including split within each country between first quartile (Q1), second and third quartiles (Q2 and Q3) and fourth quartile (Q4) in terms of energy and carbon intensity $(n=89)$ 
that the distribution is not random, and there is a difference between best and worst performing retailers).

\section{Results}

Best-performing retailer's CI and EI

According to the sample data, CI and EI best practice reference levels for food and non-food retailers were calculated applying the statistical operation first quartile (Q1). $\mathrm{CI}$ best practice threshold values for food retailers are found under $115 \mathrm{~kg} \mathrm{CO} 2 \mathrm{eq} / \mathrm{m}^{2} / \mathrm{y}$ and under $70 \mathrm{~kg} \mathrm{CO} \mathrm{CO}_{2} \mathrm{eq} / \mathrm{m}^{2} / \mathrm{y}$ for non-food retailers. Best practice $\mathrm{CI}$ threshold values of non-food retailers are $40 \%$ less than those of food retailers (Fig. 2). CI variability for food retailers reflects a factor of 18 to 1 and for non-food retailers, a factor of 17 to 1 .

EI best practice threshold values for food retailers are found under $346 \mathrm{kWh} / \mathrm{m}^{2} / \mathrm{y}$ and under $146 \mathrm{kWh} / \mathrm{m}^{2} / \mathrm{y}$ for non-food retailers. Hence, the best practice threshold values for non-food retailers is over half that of the food retailers (Fig. 3). EI variability for food retailers reflects a factor of 9 to 1 and for non-food retailers, a factor of 6 to 1 .

Store typology average EI and CI values vary, as evidenced by the retailers that specify EI and CI according to store typology (Table 1).
Best-performing retailers' policy, strategy and building practice

The business policy, strategy and building practice of best and worst performing retailers were analysed in terms of the frequency that each listed measure was reported in these retailers' sustainability/CSR reports.

As for policy, the greatest difference between best and worst performing retailers can be found in the measure "Sustainability as part of the business strategy" and in the increased use of the "Reporting Standards" category (Table 2).

Concerning business strategy, the greatest difference between best and worst performing retailers can be found in the measure "Setting up energy objectives", which can also be indirectly observed in the measures "To be $100 \%$ supplied by renewable energy"/"To be $100 \%$ carbon neutral", as well as in the measure "Include demanding energy standards in the concept of new stores and the retrofitting of existing stores" (Table 3).

Concerning building practice, the greatest difference between best and worst performing retailers can be found in the measures "Use natural refrigerants" and "Gas transfer to $\mathrm{CO}_{2}$ " in the "Refrigeration systems" category (Table 4).

Other factors can affect EI and CI, namely CSR and local culture. Hence, a geographic analysis of Q1 and

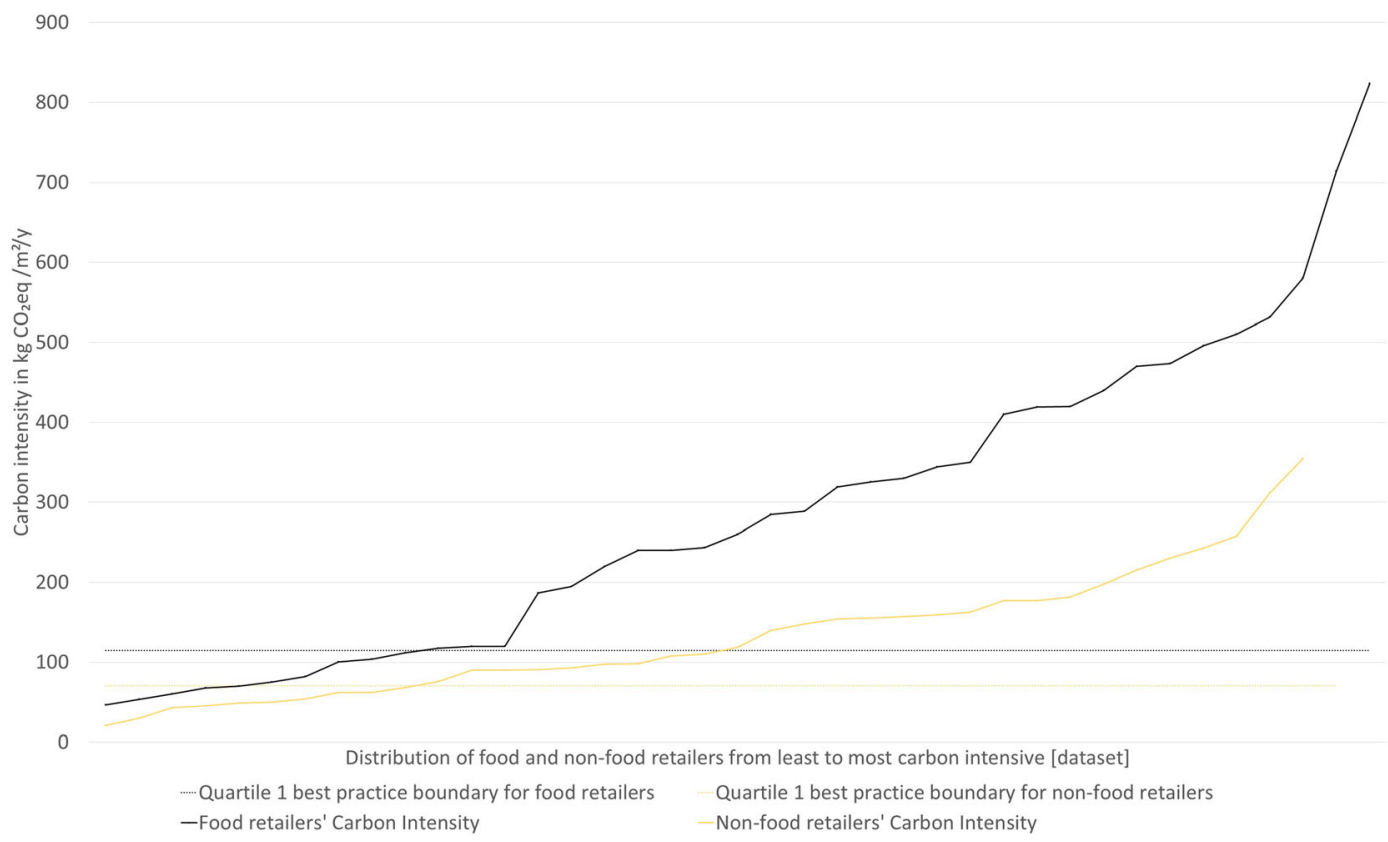

Fig. 2 Linear distribution of CI for food and non-food retailers with correspondent quartile 1 best practice boundary of each group 


\section{0}

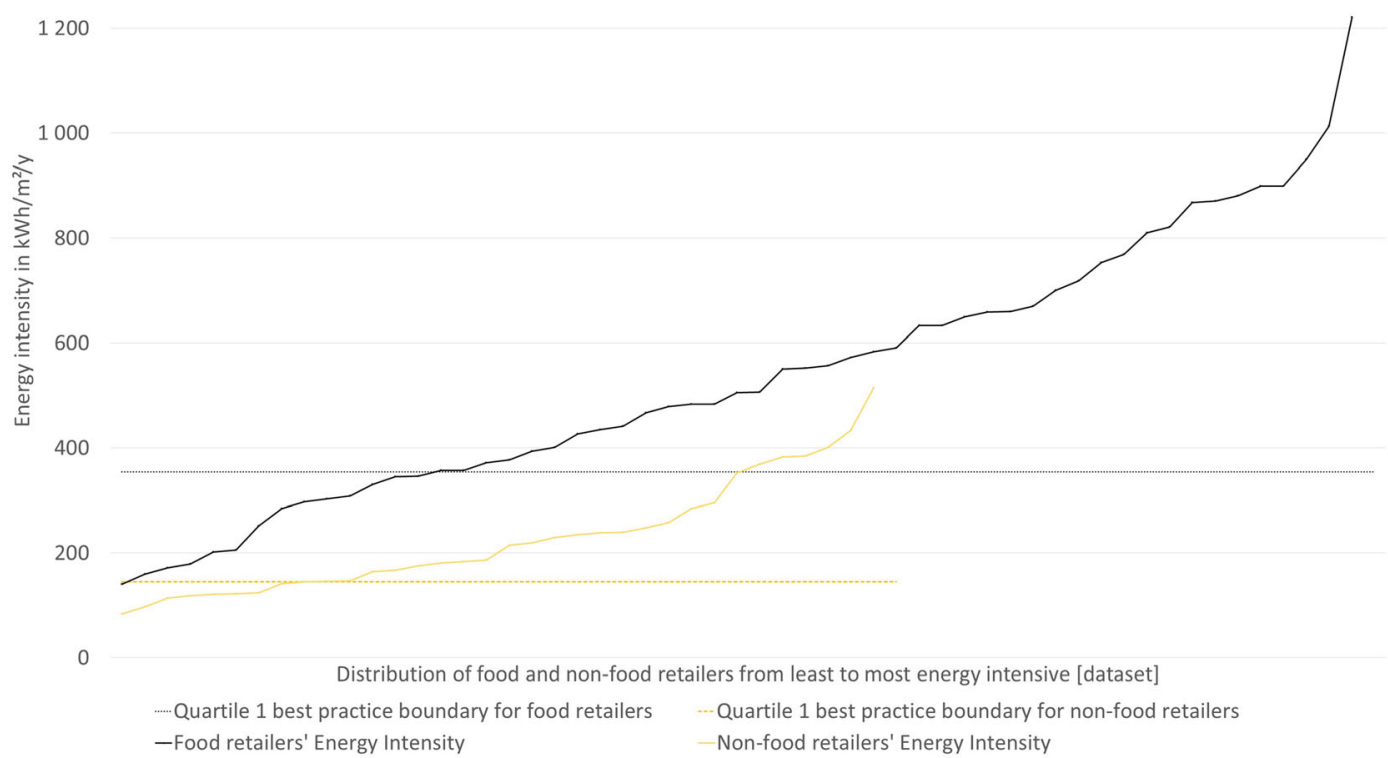

Fig. 3 Linear distribution of EI for food and non-food retailers with correspondent quartile 1 best practice boundary of each group

Q4 retailers was performed, with retailers from Scandinavian countries (Denmark, Finland, Sweden or Norway) standing out in the best-performing retailers' group (Table 5).

\section{Discussion}

The data collected on the CI and EI of the world's largest retailers have allowed to benchmark best and worst performing retailers, according to the first and third quartile statistic formulas. The factors behind CI and EI variability are concisely addressed in the subsection "Best-performing retailers' Carbon (CI) and Energy (EI) intensities", followed by the discussion of differentiating corporate measures that enable a higher environmental performance in the subsections "Bestperforming retailers' energy policy", "Best-performing retailers' energy strategy" and "Best-performing retailers' building practice".

Best-performing retailers' carbon and energy intensities

$\mathrm{CI}$ and EI benchmarks positioned best practice energy performance under $346 \mathrm{kWh} / \mathrm{m}^{2} / \mathrm{y}$ and $115 \mathrm{~kg} \mathrm{CO}$ eq/ $\mathrm{m}^{2} / \mathrm{y}$ for food retailers and under $146 \mathrm{kWh} / \mathrm{m}^{2} / \mathrm{y}$ and
$70 \mathrm{~kg} \mathrm{CO} \mathrm{CO}_{2} \mathrm{eq} / \mathrm{m}^{2} / \mathrm{y}$ for non-food retailers (Ferreira et al. 2018a, 2018b).

Results allow to conclude that both for food and nonfood retailers, store typology impacts EI and CI (Table 1), as evidenced by the retailers that specify EI and CI according to store typology. In food retail, the trend is for convenience stores to have on average higher EI and CI (as they incorporate the most intense refrigeration-systems' typology per linear meter of aisle), followed by supermarkets, hypermarkets and discount stores. A third of the best-performing food retailers are hard discount stores, whereas in the worst performing group only one retailer is a hard discounter. Low CI and EI in hard discount stores may be an indicator of the necessity of this format to be competitive, as pointed out by Ochieng et al. (2014). Other reasons for low CI and EI may relate to a greater proportion of dry packaged goods versus refrigerated food in these stores, the lack of deli or hot food counters or the lack of onsite coffee shops. In addition, hard discount is a young store format, so stores are typically newer and more energy efficient. New stores with more energy-efficient equipment may give retailers an energy efficiency advantage.

In non-food retail, the trend is for department stores and apparel/footwear stores to have on average higher $\mathrm{EI}$ and $\mathrm{CI}$ and for home improvement, decoration stores and auto-shops to have the lowest EI and CI (Table 1). 
Table 1 EI and CI breakdown per retail sub-type

\begin{tabular}{|c|c|c|}
\hline Retail sub-type & Average energy intensity in $\mathrm{kWh} / \mathrm{m}^{2} / \mathrm{y}$ & Average carbon intensity in $\mathrm{kg} \mathrm{CO}_{2} \mathrm{eq} / \mathrm{m}^{2} / \mathrm{y}$ \\
\hline \multicolumn{3}{|l|}{ Food retailers } \\
\hline Discount stores ${ }^{1}$ & 555 & 226 \\
\hline Hypermarkets $^{2}$ & 591 & 258 \\
\hline Supermarkets ${ }^{3}$ & 584 & 273 \\
\hline Convenience stores ${ }^{4}$ & 941 & 568 \\
\hline \multicolumn{3}{|l|}{ Non-food retailers } \\
\hline Home improvement/DIY stores ${ }^{5}$ & 150 & 130 \\
\hline Furniture/decoration stores ${ }^{6}$ & 165 & 60 \\
\hline Auto-shops ${ }^{7}$ & 169 & 82 \\
\hline Electronics/household appliances stores ${ }^{8}$ & 212 & 106 \\
\hline Drug stores/pharmacies ${ }^{9}$ & 220 & 160 \\
\hline Department stores ${ }^{10}$ & 283 & 175 \\
\hline Apparel/footwear stores ${ }^{11}$ & 321 & 161 \\
\hline \multicolumn{3}{|c|}{$\begin{array}{l}{ }^{1} \text { Discount stores: with average surface less than } 1000 \mathrm{~m}^{2} \text {, in stand-alone buildings (usually owned) or building units (usually rented) } \\
\text { (Galvez-Martos et al. 2013; Schönberger et al. 2013) }\end{array}$} \\
\hline \multicolumn{3}{|c|}{$\begin{array}{l}{ }^{2} \text { Hypermarkets: with high sales area, low relative refrigeration load compared with food supermarkets and in stand-alone buildings, usually } \\
\text { owned (Galvez-Martos et al. 2013; Schönberger et al. 2013) }\end{array}$} \\
\hline \multicolumn{3}{|c|}{$\begin{array}{l}{ }^{3} \text { Supermarket: with high refrigeration load, surface from } 1000 \text { to } 3000 \mathrm{~m}^{2} \text {, can be in stand-alone buildings (usually owned) or building units } \\
\text { (usually rented) (Galvez-Martos et al. 2013; Schönberger et al. 2013) }\end{array}$} \\
\hline \multicolumn{3}{|c|}{$\begin{array}{l}{ }^{4} \text { Convenience stores: small stores with refrigeration of food. Building units are usually rented (Galvez-Martos et al. 2013; Schönberger et al } \\
\text { 2013) }\end{array}$} \\
\hline \multicolumn{3}{|c|}{$\begin{array}{l}{ }^{5} \text { Home improvement/do-it-yourself (DIY) stores sell household hardware for home improvement, repair equipment, materials and garden } \\
\text { accessories }\end{array}$} \\
\hline \multicolumn{3}{|c|}{${ }^{6}$ Furniture/decoration stores sell home accessories and furniture } \\
\hline \multicolumn{3}{|c|}{${ }^{7}$ Auto-shops deal in the repair of automobiles } \\
\hline \multicolumn{3}{|c|}{${ }^{8}$ Electronics/household appliances stores sell electronic equipment intended for everyday use; } \\
\hline \multicolumn{3}{|c|}{${ }^{9}$ Drug stores/pharmacies sell cosmetics, toiletry items, first-aid supplies and medications } \\
\hline \multicolumn{3}{|c|}{${ }^{10}$ Department stores sell an extensive assortment of goods, organized into separate departments } \\
\hline & & \\
\hline
\end{tabular}

This may be explained through different marketing and pricing strategies, reflecting distinct needs of each store format as how to effectively display merchandise and how to provide comfort and store ambiance for customers, which in turn will affect lighting, HVAC and equipment requirements.

In addition, it was found a tendency for store location to impact EI, as evidenced by the retailers that specified EI per retail sub-type and per country. These results suggest that EI variability within in European countries is lower than that of other continents. Nevertheless, the fact that within Europe, stores located in countries with different climate conditions, have similar EI values, points to the existence of other more important factors affecting the EI than climate conditions (Ferreira et al. 2018a, 2018b), such as location, opening hours, occupancy, staff behaviour, maintenance routines, store size, store volume, the nature of products being retailed, type, building age, equipment's efficiency (Spyrou et al. 2014) or even local government regulation or building incentives.

We also found a tendency for best-performing retailers to have less stores than worst-performing ones (36\% versus $64 \%$ for food retailers and $44 \%$ versus $56 \%$ for non-food retailers). In addition, retailers with green store concepts for new buildings claim to be able to achieve $30-70 \%$ of the traditional store EI as a result of incorporating high-performance sustainable solutions (Aeon 2015; Aldi 2015; Lidl 2015), which stresses the importance energy-efficient equipment to achieve low 


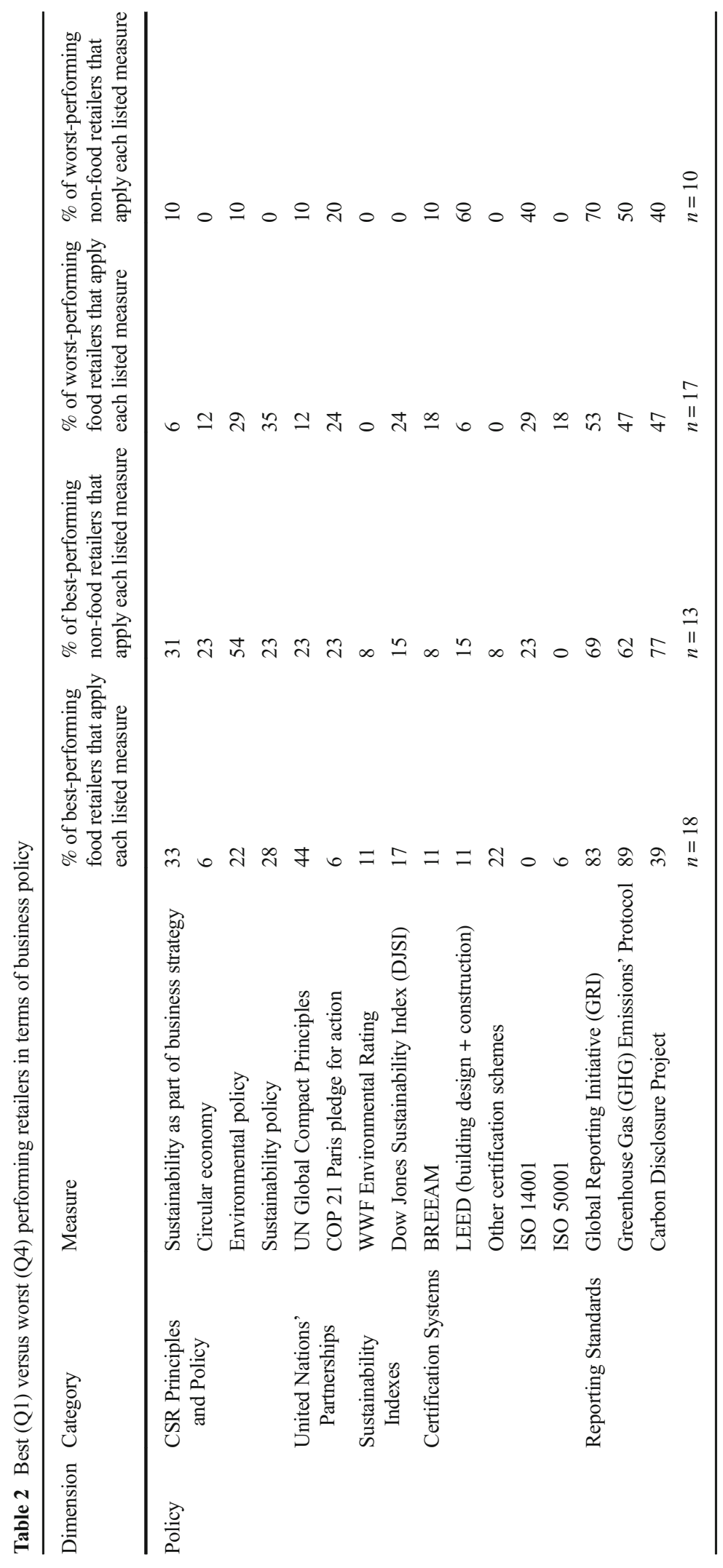




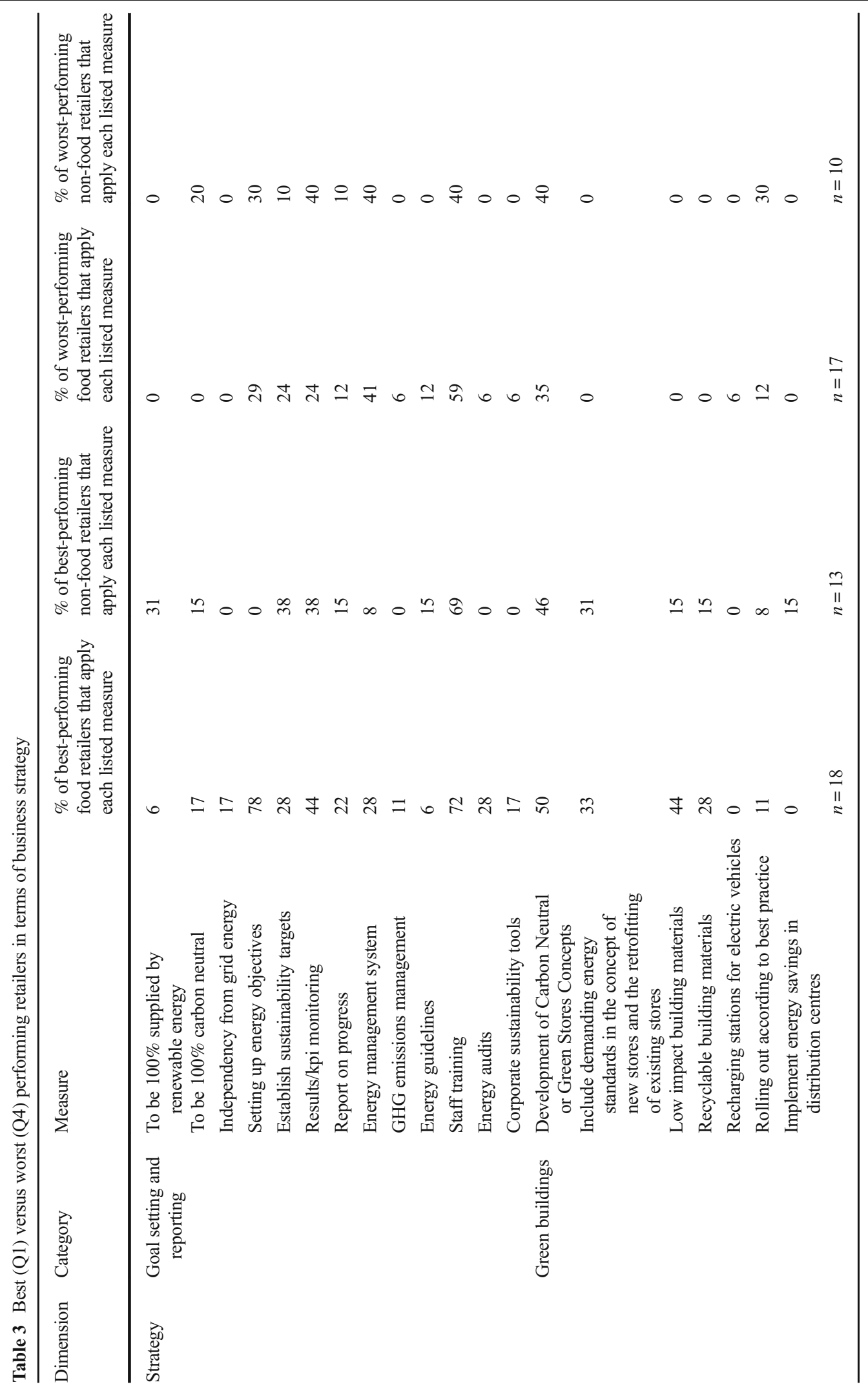




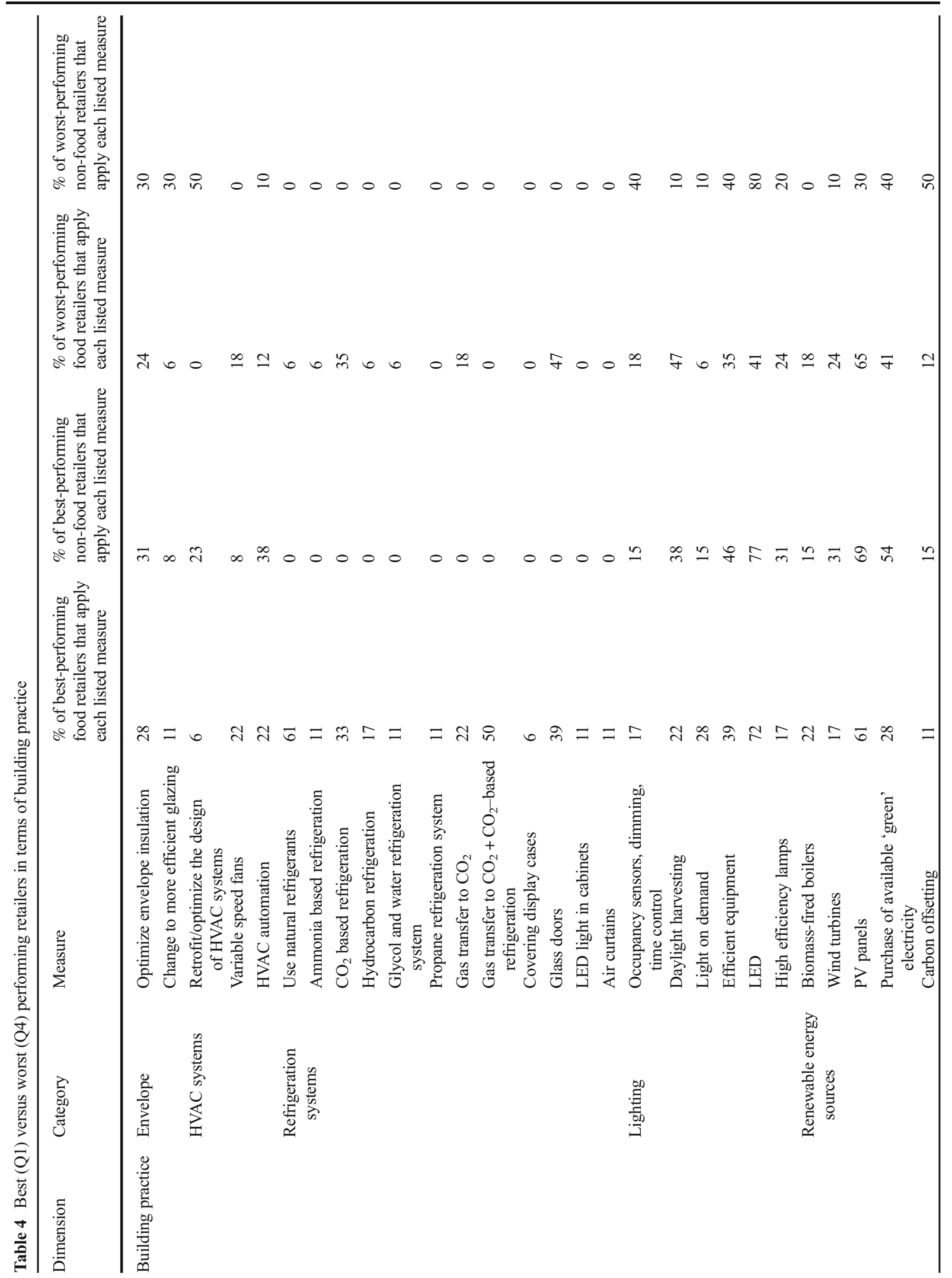


EI. Some retailers specified the EI of traditional stores versus the EI of new, more energy-efficient ones, such as Rewe (950 vs $500 \mathrm{kWh} / \mathrm{m}^{2} / \mathrm{y}$ ) (Rewe 2017) or Edeka (357 vs $104 \mathrm{kWh} / \mathrm{m}^{2} / \mathrm{y}$ ) (Edeka 2016). Other retailers have specified the reductions on the energy consumption they are able to achieve by introducing energy efficient technology in new or refurbished stores, such as Lidl (claiming energy savings of $40 \%$ overall) (Lidl 2015) or Aldi (claiming energy savings of $30 \%$ overall) (Aldi 2015). Newer stores, utilizing newer equipment (and lighting) are inherently more energy efficient, as demonstrated by these retailers. In fact, Lidl claims $40 \%$ of energy savings when using LED lighting and an additional $30-40 \%$ when using low-energy refrigeration systems, coupled with glass doors on cabinets.

Other factors that affect EI include the price and availability of local electricity generation and local culture (Ferreira et al. 2018a, 2018b). In fact, corporate culture and social responsibility must also impact CI and EI, as most of the best-performing retailers are from countries with leading climate change performance (Burck et al. 2019): Switzerland, Denmark, Finland, Sweden or Norway. Indeed, there are no retailers from these nationalities in the worst performing retailers' group (Table 4). By analysing the compared nationality percentage of best-performing retailers versus worst performing retailers, it is possible to suggest that policy at national and international levels play a role at pushing retailers into energy and carbon efficiency, namely in the decarbonizing strategies and goals set by retailers. Nevertheless, it is rather retailers' CSR approach that is a differentiating factor in terms of energy and carbon performance - the differences of energy and GHG emissions' reduction goals within European retailers with a common legislative framework, are evidence of such. The differences of EI and CI performance within European countries with a common legislative framework are further evidence of such. Likewise, developing countries like Brazil and Philippines ranking amongst best-performing retailers also attest to the role of CSR in environmental performance.

CI variability was greater than that of EI, particularly for non-food retailers, which is consistent with the findings of Schönberger et al. (2013), placing the carbon footprint of retail companies as highly dependent on electricity use $-60 \%$ for food retailers and higher for non-food retailers, due to the absence of refrigeration systems (Schönberger et al. 2013). Carbon intensity is thus affected mostly by the carbon content of purchased 


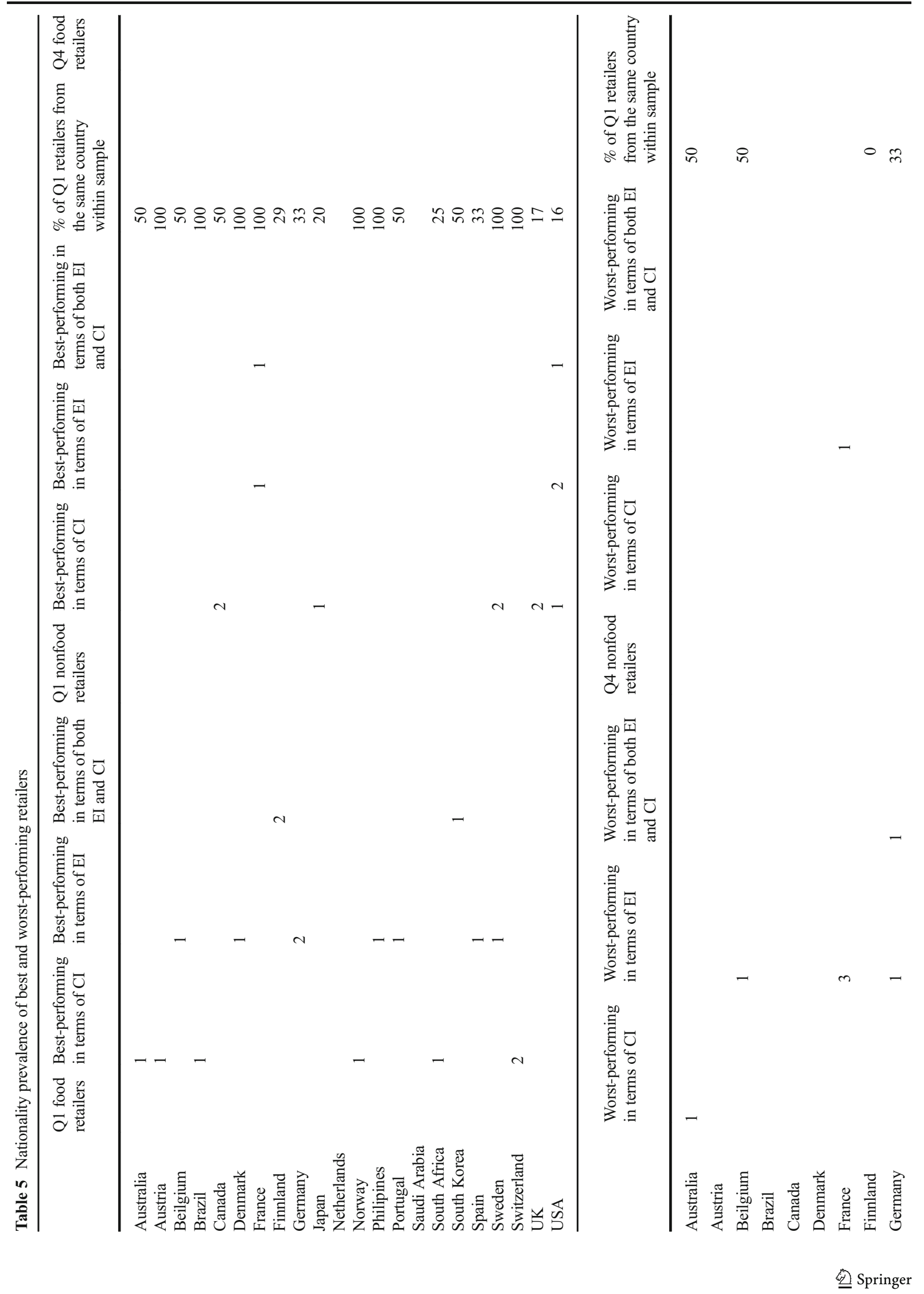




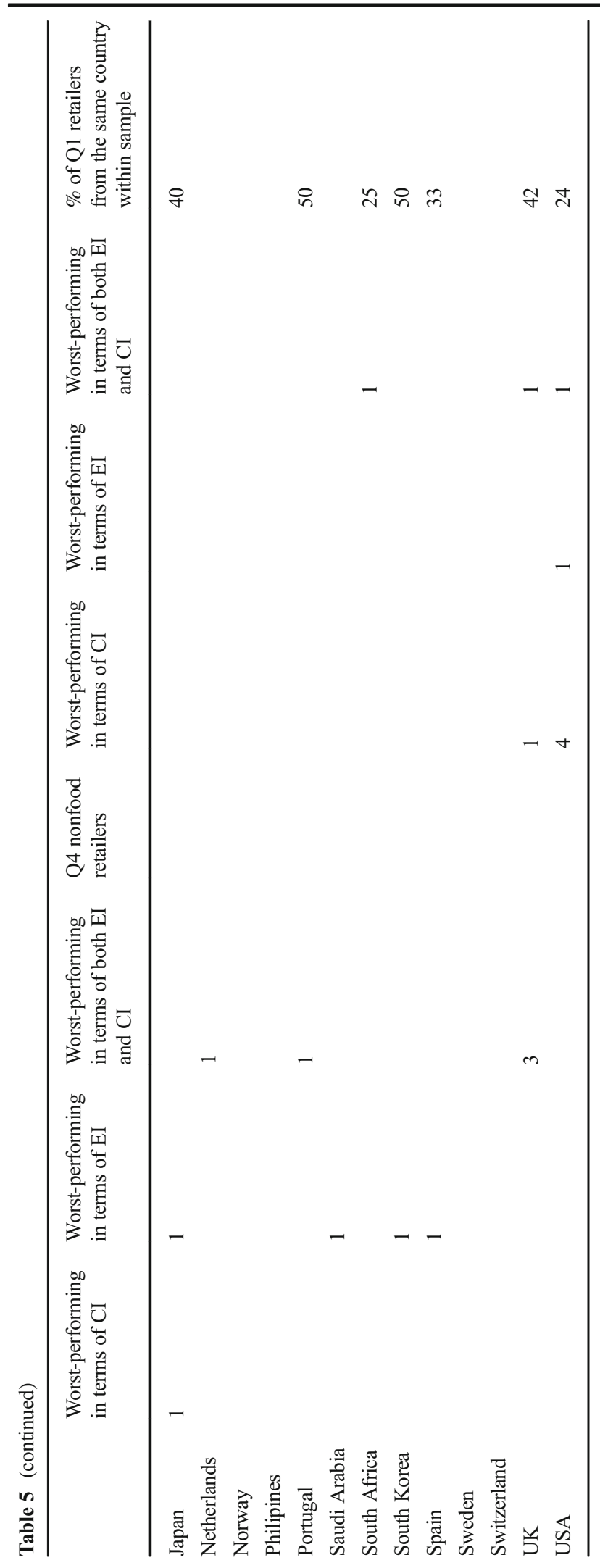


electricity in the countries in which a retailer is active. Low carbon energy, mainly when not generated on-site by the retailers but evidenced from guarantees of origin, may thus impact CI results. However, as no retailer has specified CI per retail per country, the exact impact of the energy mix in CI variability remains to be determined. In general terms, CI variability is a result of the energy-efficiency strategies to minimize the consumption of energy and of the energy's production source (fossil vs. renewable energy). For food retailers, it also results from unintentional refrigeration systems' fugitive emissions (ENDS Carbon-University of Edinburgh Business School 2009). Therefore, the variability found in the present study both for CI and EI values supports the theory that, in order to decrease retailers' carbon footprint, EI reduction should first be addressed (Schönberger et al. 2013).

To mitigate scope $1 \mathrm{GHG}$ direct emissions, namely stationary combustion for comfort heating, food retailers can recover waste heat from the refrigeration cycle, hence suppressing the need for additional store heating. To address fugitive emissions resulting from the unintentional release of GHG from refrigerant systems, retailers can invest in gas leakage detection and improved maintenance in HVAC and refrigeration systems. The later can minimize food retailers' carbon footprint by up to $30 \%$ (Schönberger et al. 2013). Gas transfer to $\mathrm{CO}_{2}$ in refrigeration systems also ranks high for European food retailers, because of its impact on the company's overall carbon footprint. In addition, to mitigate scope $2 \mathrm{GHG}$ indirect emissions from the consumption of purchased electricity, retailers can invest in the on-site production of renewable energy, in the purchase of green energy or in offsetting methods. Energy efficiency solutions minimising energy consumption are the first step to decrease emissions from the electrification process. Thus, to achieve significant CI and EI reductions, a multidimensional corporate approach needs to be considered, integrating several materiality issues in business policy, strategy and building practice.

\section{Best-performing retailers' energy policy}

When comparing best with worst performing retailers in terms of energy policy, the greatest difference can be found in the measure "Sustainability as part of the business strategy", reported by $33 \%$ and $31 \%$ bestperforming food and non-food retailers respectively against $6 \%$ and $10 \%$ worst performing food and non- food retailers respectively. The results show that integrating sustainability as part of the business strategy has a positive effect on best-performing food retailers $(p=$ 0.04). Best-performing retailers that integrate sustainability as a part of their business strategy invoke for such improved business resilience, cost reduction across the value chain, brand differentiation or social responsibility towards the environment, which is analogous to the findings of Galvez-Martos et al. (2013). This also attests the findings of Testa et al. (2017), according to whom a firm's "greening" strategic profile plays a role in setting them apart from competitors. In best-performing nonfood retailers, there was a positive effect regarding the adoption of an environmental policy $(p=0.03)$. Contrary, no important differences between best and worst performing food retailers were found in the measures "environmental policy", often associated with an environmental management system (EMS). This can be explained by the different level of corporate internalization of the environmental management system in terms of strategies and daily operational procedures between best or worst performing retailers, therefore, leading to different results in terms of environmental performance. According to Testa et al. (2017), deeper internalization of an environmental management system can be achieved with wider and more frequent employee involvement or higher integration with other management and operational tools, as is the case of the bestperforming retailers in the present study, in relation to staff training, energy audits and development of corporate sustainability tools (see the "Best-performing retailers' energy strategy" section).

Similarly, the results show that worst performing food and non-food retailers report increased use of the ISO 14001 certification. In fact, for worst-performing food retailers, there was a positive effect regarding the adoption of ISO $14001(p=0.01)$, suggesting that adopting a meta-standard does not necessarily lead to a better environmental performance. Voluntary standards emerged as global regulatory mechanisms to address sustainability, quality, health and safety in organizations (Tuczek et al. 2018). This proves that a mimetic strategy with the purpose of being compliant with a standard - as that potentially led by worst performing retailers - will fail in terms of achieving the same result as a bestperforming competitor (Testa et al. 2017). The same is also likely true for the use of ISO 50001: only one bestperforming food retailer has mentioned the use of this standard, against three worst performing food retailers. 
Additionally, two best-performing retailers have issued Energy Policy statements that do not mention this norm. The fact that retailers are not commenting on the use of ISO 50001 in their sustainability/CSR reports is not an irrefutable proof that they do not use the standard (although evidence does not support the opposite hypothesis either). In fact, most best-performing retailers (68\%) mention the use of an energy management system (e.g., a system that monitors and adjusts the energy consumption of stores), coupled with energy goal setting and monitoring, which may hint at the possibility of retailers to resort to ISO 50001 as a more structured framework for operational energy management.

No relevant differences were found concerning sustainability indexes (namely the Dow Jones Sustainability Index) between best and worst performing food and nonfood retailers. Sustainability Indexes are another way of promoting environmental, social and governance (ESG) issues in the retail industry, tracking companies with strong sustainability profiles (MSCI 2017). In fact, investors are attracted to sustainability for its superior risk-return profiles and because sustainability stands for informed and disciplined management (Choi and Gray 2008).

A management culture based both on legal requirements and voluntary obligations is transversal to best and worst performing retailers as a way of incurring some goodwill with consumers (Richman and Simpson 2016), as well as partnerships with NonGovernment Organizations (NGOs). Both bestperforming food and non-food retailers adhere to the UN Global Compact Principles (44\% and 23\% bestperforming food and non-food retailers respectively vs $12 \%$ and $10 \%$ worst-performing food and non-food retailers respectively), with a positive effect $(p=0.03)$ for best-performing food retailers. Opposite, there are no important differences in the adherence to the COP 21 Paris Pledge for Action by either best or worstperforming food and non-food retailers. Whereas the UN Global Compact provided a framework for improving the analysis of ESG issues in corporate investments, the COP 21 Paris Pledge for Action invited signatories to support the objectives of the Paris Agreement. The use of reporting standards is largely reported by retailers, with best-performing food retailers adhering more than worst performing ones (83\% vs $53 \%$ for GRI standards and $88 \%$ vs $47 \%$ for the GHG Protocol). In fact, there was a positive effect regarding the adoption of GRI standards $(p=0.05)$ and of the GHG Protocol $(p=0.01)$ for best-performing food retailers. This attests to best-performing food retailers' effort to bring consistency and transparency on energy accounting tools, as to reduce limitations in calculation methodologies concerning data comparability. In addition, voluntary standards tend to signal positive environmental performance and deter companies from greenwashing (Hahn and Luelfs 2014; Kim and Lyon 2015; Parguel et al. 2011). GRI reporting standards, followed by most bestperforming retailers, help to overcome greenwashing tendencies by reporting both positive and negative aspects of sustainability performance (Hahn and Luelfs 2014).

Voluntary green building certification systems have become increasingly popular as a means for achieving sustainability in the built environment (Borgstein et al. 2016) and of mitigating the negative impacts associated with construction (Shi et al. 2016). About half of the studied retailers reported the use of a Green Building Certification System, usually chosen according to retailers' geographic provenance. BREEAM, as a European certification system, was chosen uniquely by European retailers. Besides, European retailers report the use of other national building certification schemes, such as Germany's Sustainable Building Council (DGNB), France's Haute Qualité Environnementale (HQE), Switzerland's Sustainable Construction Standards (SNBS) or Sweden's Green Building Council (SGBC). In addition, there was a positive effect regarding the adoption of other green building certification systems $(p=0.04)$ for best-performing food retailers. In contrast, LEED, as an American certification system, was chosen by all American retailers, by four European retailers and by one Asian retailer. Hence, LEED was the most popular green building certification system, reported both by best $(26 \%)$ and worst $(66 \%)$ performing retailers overall. Differences seem to exist in the approach of best-performing retailers to green building design, as only they include demanding energy standards in the concept of new stores and the retrofitting of existing stores (see the "Best-performing retailers' energy strategy" section). The fact that LEED appears to have been used mainly by retailers in the worst-performing retailers - with a positive effect ( $p=$ 0.03 ) for worst-performing non-food retailers - could suggest they are greenwashing, as LEED certifications, may only have been achieved in few stores and not replicated across retailers' property portfolio. It could also reflect more on other factors, such as the carbon intensity of US electricity and the large summer-winter temperature difference in continental USA, than on 
voluntary actions. Since the number of certified green stores stands as a key performance indicator of environmental management, their percentage in retailers' portfolio is expected to increase.

Business models do change and these changes can have an important influence on GHG emissions (Sullivan and Gouldson 2013). If reducing operational emissions remains a priority for all retailers (Sullivan and Gouldson 2013), customer preference, revenue growth and access to natural resources stand as additional environmental business drivers for bestperforming retailers, that believe their commitment to sustainability will yield long-term economic performance to the organization.

Best-performing retailers' energy strategy

Setting up energy objectives as an energy-related business strategy was the most popular measure declared by retailers $(78 \%$ in best-performing food retailers vs about $30 \%$ in worst performing food and non-food retailers). Indeed, there was a positive effect regarding this measure for both best-performing food retailers $(p=0.004)$ and worst-performing non-food retailers $(p=0.03)$. Nevertheless, best-performing retailers convey the will to consider radical changes in their business models in order to tackle climate change, such becoming $100 \%$ supplied by renewable energy (with positive effect $(p=0.05)$ for bestperforming non-food retailers) or carbon neutral by 2020. Those who do not target at carbon neutrality set energy and carbon reduction goals that range from 20 up to $85 \%$, by 2020 . Drivers for energy reduction targets and strategies include climate change ethical considerations alongside rising energy prices, as pointed by Christina et al. (2015). Contrary, worst performing retailers do not share carbon neutrality goals, and the two retailers that do advocate it, either do not indicate the year to accomplish targets or push them to 2050 .

There are no important differences in the reported use of energy and GHG emissions' management systems both for best and worst-performing food and non-food retailers. For food retailers, GHG emissions' management systems are important tools to decrease their carbon footprint, since $30 \%$ of it can derive from refrigeration systems' gas leakage (WRI and WBCSD 2016).

Staff training is the most reported energy management measure overall, whereas energy audits are rarely reported by worst performing food retailers, despite being an important tool to identify energy optimization areas. Additionally, the use of specific corporate sustainability tools or apps on carbon footprint has been reported by retailers as novel ways to raise environmental awareness amongst associates.

In terms of green building design, both best and worst performing food and non-food retailers develop carbon neutral or green store concepts as a way of promoting environmental concern. However, only best-performing retailers include demanding energy standards in the concept of new stores and in the retrofitting of existing stores (with positive effect for best-performing food $(p=0.01)$ and non-food retailers $(p=0.05))$. This suggests that best-performing retailers understand the importance of a structured approach to innovation to achieve energy-efficiency and carbon neutrality, as argued by Sullivan and Gouldson (2013). The integration of low impact building materials $(p=0.002)$ and recyclable building materials $(p=0.02)$ also have a positive effect for best-performing food retailers. Additionally, soft mobility principles and of recharging stations for electric vehicles, as well as of lean principles to identify areas of wasted resources, are also trends mentioned by best-performing retailers.

In addition, best-performing retailers seem to be willing to endure higher initial construction costs, with longer payback periods, as they believe that green buildings allow lower running costs, enhance property assets and improve the wellbeing for customers and teams, which in turn may translate to a better shopping experience and increased sales. The use of low impact building materials is also reported more frequently by bestperforming retailers as well as the use of recycled building materials. This corroborates the findings of Ochieng et al. (2014) and of Richman and Simpson (2016), given that best-performing retailers' initiatives to build energy-efficient stores are driven as much by business imperatives as by commitments to sustainability. Nonetheless, green building concepts are tested both by best and worst performing retailers in pilot projects. For bestperforming retailers, once a technology is proven, it is immediately rolled out to other existing stores, which in turn improves the energy-efficiency of the company overall. Such may not be the case for worst performing retailers, which do not disclose the speed of this process.

Best-performing retailers' building practice

According to Schönberger et al. (2013), the average share for energy consumption for a food retailer is 
$50 \%$ for refrigeration, $25 \%$ for lighting, $20 \%$ for HVAC systems and 5\% for electric appliances and other internal processes. For non-food retailers, the map for the energy consumption of a store depends more on business typology though lighting, HVAC systems and electric appliances and other internal processes remain the three most important energy consumption segments. Given the positive correlation between EI and CI, measures that contribute the most to environmental performance are those that allow decreasing the energy consumption of the most energy-intensive store segments (in order, refrigeration, lighting, HVAC and electric appliances and others internal processes). In addition, the most common energy-efficiency solutions reported by best and worst performing retailers are economically and environmentally driven: $\mathrm{CO}_{2}$-based refrigeration, glass doors in frozen cabinets (exclusively for food retailers), LED lighting, efficient equipment and either photovoltaic energy produced on site or the purchase of available "green" electricity. $\mathrm{CO}_{2}$-based refrigeration and glass doors in frozen cabinets can reduce energy consumption by $40 \%$, whereas LED lighting systems can reduce energy consumption by $50 \%$, when compared with fluorescent T8 lighting (CommONEnergy Project 2013a; Schönberger et al. 2013). Besides, the replacement of old rooftop units by more efficient equipment can reduce the energy consumption of HVAC systems in $20 \%$, improving thermal conditions for customers at the same time (CommONEnergy Project 2013b). Differences were found in the higher percentage of best-performing food that reported the use of LED ( $72 \%$ vs $41 \%$ ). For food and non-food retailers alike, the main difference was found in the use of HVAC automation $(22 \%+38 \%$ best-performing retailers vs $12 \%+10 \%$ worst-performing retailers).

Despite this, the greatest difference between best and worst performing food retailers was found regarding the use of natural refrigerants in refrigeration systems (with a positive effect $(p=0.001)$ for best-performing food retailers). Best-performing food retailers promote gas transfer to $\mathrm{CO}_{2}$ in existing stores systems (with a positive effect of $p=0.0007$ ) and trial more alternative solutions with refrigerants with lower Global Warming Potential (GWP) than worst-performing food retailers. The use of natural refrigerants comes in line with recent regulation regarding F-gases, such as the Kigali Amendment to the Montreal Protocol, or the European Union F-Gas Regulation No 517/2014, intending at a largescale conversion to climate-friendly technologies in new equipment and products by 2030 (European Parliament and European Council 2014). According to data collected, it is not possible to identify the impact of new stores, with more efficient equipment (purchased after update of the F-gases regulation), in each of the retailers overall EI and CI performance. Some retailers-especially the so-called "hard discounters" have expanded their store base rapidly in recent years into many new markets, which may affect their average EI/CI. In fact, that prevalence of a third of hard discount retailers in the group of best-performing retailers points at this possibility. Nonetheless, differences in CI performance between best and worst performing retailers could be explained by the speed rate at which gas transfer to lower GWP refrigerants has occurred in existing stores, alongside with complementary fugitive GHG emissions' detection measures, such as gas leakage detection programs.

When choosing alternative refrigeration gases, retailers are opting for refrigerants with the lowest possible GWP, like $\mathrm{CO}_{2}$ (provided local climate conditions allow it), with best-performing retailers further trialling alternative refrigeration solutions, namely Hydrocarbon, ammonia, propane and glycol and water refrigeration systems. The choices for natural refrigeration seem related to company choice and to decisions that support good EI/CI performance, instead of merely responding to legislation. Nonetheless, some retailers may not have direct control in refrigeration systems, namely, if they customarily operate out of leased property where the landlord is responsible for cooling.

Most (90\%) of the best-performing retailers have equally good levels of performance in EI and CI. Exceptions to this rule are two best-performing retailers that exhibited first quartile CI levels and third quartile EI levels. This result could be explained by the use of renewable energy or by purchasing green electricity, with a relatively small investment in energy efficiency. In fact, these retailers are Canadian, which ties into the comment above about the carbon intensity of electricity, given Canada's strong reliance on hydro and nuclear energy (Natural Resources Canada 2019). In contrast, one best-performing retailer exhibited first quartile EI levels and fourth quartile CI levels, which could mean the opposite. Similarly, most worst performing retailers (52\%) have equally poor levels of performance in EI and CI. Exceptions to this rule are two best-performing retailers which exhibited fourth quartile CI levels and second quartile EI levels, which could be explained by the use of fossil energy despite the use of some energy efficiency solutions. 
Energy-efficiency and $\mathrm{CO}_{2}$-based refrigeration are the consensual priority amongst best and worst performing retailers when introducing sustainable high-performance solutions in their stores. This is above all because of the potential high energy-cost savings and because energy efficiency, as well as refrigerants with lower GWP, contribute to the reduction of GHG emissions. Additionally, best and worst performing retailers tend to invest both in passive and active sustainable building solutions, including a better-insulated envelope, daylight harvesting and more efficient glazing. In fact, the general trend is for retailers to obtain consistent improvements in energy efficiency over time, as argued by Sullivan and Gouldson (2013). In fact, the top highperformance solutions mentioned by best and worst performing retailers in the present study are in line with the findings of Sullivan and Gouldson (2013), Richman and Simpson (2016) and Ochieng et al. (2014), naming LED lighting, refrigeration and HVAC as key areas where attention is typically given by retailers to improve energy efficiency. Reducing energy demand ultimately means an increase in efficiency through a reduction in waste (Price 2010), with energy-efficiency solutions minimising energy consumption are the first step to decrease GHG emissions. Nonetheless, the fact that building solutions are used by both best and worst performing retailers points to differences in the way these solutions are incorporated across retailers' property portfolio. This could suggest that worst performing retailers are greenwashing, or just that using highperformance building solution sporadically will fail in terms of achieving the same environmental performance as best-performing retailers. Furthermore, it points to the existence of a behavioural inconsistency between 'stated' business energy efficiency and 'actual' business energy efficiency, with best EI and CI resulting also from proper attention given to property management (leasing agreements), facility management (maintenance), tenants behaviour (consumption of energy), construction management (new stores) and ownership (investments' funding and value).

The wide array of high-performance energy-efficient solutions used by best and worst performing retailers shows that there is no "silver bullet" to achieve nearly zero energy buildings (nZEBs), but rather, a combined approach of energy-efficient and low-carbon solutions, coupled with behavioural change. Other studies suggested similar strategies (Jenkins 2008; Sullivan and Gouldson 2013; Thompson 2007). Nonetheless, for large organizations with massive quantities of buildings the nZEBs do not seem to be a real target but rather increased sustainability across all the systems. This is partly due to the distribution of utilities and their infrastructure, as it is cheaper and better to pay a reasonable price for the service than it is to buy specialized materials and services that substitute for the utility service. In certain cases, regulatory requirements may even hamper the independence of buildings from the service grid.

As no single parameter is responsible for low CI or EI, an integrated design approach that takes into account climate, technology, occupant behaviour, and maintenance should be implemented to maximize energy efficiency and minimize GHG emissions (Jiang and Keith Tovey 2009; Li et al. 2014). In parallel, to decrease GHG emissions and improve carbon efficiency, food retailers can recover waste heat from the refrigeration cycle and invest in gas leakage detection and in improved maintenance in HVAC and refrigeration systems. Moreover, food and non-food retailers can invest in the on-site production of renewable energy, namely solar, in the purchase of green energy or in carbon offsetting methods. Technologies that will make a difference in the future will be those that can promote energy-efficiency and the reduction of GHG emissions, combined with passive building solutions that minimize the consumption of energy.

\section{Limitations}

Firstly, some of the retailers' data collected online could be outdated as not all retailers publish sustainability/ CSR reports on a yearly basis. In addition, analysing only the most recent reports (from the fiscal year 2016) may produce different results than analysing reports from the previous 10 years.

Secondly, analysing retailers according to their country of origin may induce potential bias in the EI/CI results, as there is an inherent risk where individual retailers are consolidating their energy and carbon data from several countries in different parts of the world, with different climates, store formats and electricity sources. Likewise, the categorisation of retailers within the food/non-food group according to the predominant number of stores may also induce potential biases. Results accuracy would be sounder had data been disaggregated and reported by each country and by retail type by most retailers.

Thirdly, it is important to notice that identifying the most energy or carbon-efficient retailers through $\mathrm{CI}$ or 
EI (particularly for food retailers) is not straightforward. This is mainly due to the considerable variation in the amount of refrigerated food that companies retailed as a proportion of their overall activity (ENDS CarbonUniversity of Edinburgh Business School 2009), with direct impact on their CI or EI. For future research, a more-in-depth investigation of one type of retailer (such as a supermarkets' one) could be of value.

Fourthly, best-performing retailers are qualified as those with best practice CI or EI. Even though the use of the first quartile to define the upper limit of best practice can be questioned, best practice benchmarks defined by the first quartile upper limit represent a high environmental performance level, far better than good or average performance. The same holds true for worst practice retailers, on the opposite end, defined by the lower limit of the third quartile. Nevertheless, by looking only at retailers for which data is publicly available, benchmarks could be biased as bestperforming retailers may have an advantage in presenting EI or CI data, but worst-performing retailers may not. Drawing inferences from small sub-sample sizes may also potentially bias conclusions.

Lastly, the analytical categories recorded under each variable's table (policy, strategy and building practice) were agreed upon by all authors (an architect with 12 years of work experience in retail stores, an environmental engineer expert in green building certification systems, a civil engineer specialised in sustainable construction and a civil engineer specialised in buildings' refurbishment). Nonetheless, bias can derive from the selectivity of these authors in terms of data coding.

To make comparisons of EI and CI more robust, the analysis of other relevant normalizing factors, such as local climate and weather, local government regulation or incentives, is necessary in future studies. Likewise, the analysis of conventional performing retailers (from the second and third quartiles) could further stress or provide new findings to the current investigation. Further research works could also focus on the links between CI and EI and on the effect on EI and CI of specific policies, strategies or technology sets.

\section{Conclusion}

By analysing the policy, strategy and building practice of the best EI and CI performing retailers in comparison with the worst performing ones, this study set out to identify the measures that contribute most to the retailers' enhanced environmental performance like energy and carbon. Our key findings are as follows:

- Combined CI and EI best practice threshold values are found simultaneously under $346 \mathrm{kWh} / \mathrm{m}^{2} / \mathrm{y}$ and $115 \mathrm{~kg} \mathrm{CO} 2 \mathrm{eq} / \mathrm{m}^{2} / \mathrm{y}$ for food retailers and under $146 \mathrm{kWh} / \mathrm{m}^{2} / \mathrm{y}$ and $70 \mathrm{~kg} \mathrm{CO} \mathrm{CO}_{2} \mathrm{eq} / \mathrm{m}^{2} / \mathrm{y}$ for nonfood retailers;

- In terms of policy, best-performing food retailers share a strong top-down management commitment towards sustainability across all business areas ( $p=$ 0.04 ) and an increased use of referential reporting standards, particularly of GRI standards $(p=0.05)$ and of the GHG Protocol ( $p=0.01)$, suggesting that high levels of corporate internalization of the environmental management systems lead to a higher environmental performance;

- The contrapositive is also likely true: a lack of strong top-down broad commitment towards sustainability across all business areas will not yield a best performance in CI and EI: low levels of corporate internalization of the environmental management systems lead to a poorer environmental performance, evidenced by worst performing retailers' dependency on external drivers to achieve sustainability standards;

- In terms of strategy, best-performing retailers establish ambitious energy goals, such becoming 100\% supplied by renewable energy $(p=0.05)$ or carbon neutral by 2020 . Best-performing food $(p=0.01)$ and non-food retailers $(p=0.05)$ include demanding energy standards in the concept of new stores and existing stores;

- As for building practice, LED and photovoltaic technology are amongst the most popular highperformance sustainable solutions. Nevertheless, only the use of natural refrigerants $(p=0.001)$ and gas transfer to $\mathrm{CO}_{2}(p=0.0007)$ were related to bestperforming practice;

- The variability of CI and EI found in this study demonstrates that it can be possible to reduce the retail sector's contribution to global GHG emissions considerably, which would impact decisively and positively the environmental performance of this industry.

These findings are of immediate interest and application to retailers, confirming that a higher 
environmental performance is possible, in turn, attaining a more resilient, sustainable business. These findings are also of immediate interest and application to architects, engineers when considering the design and operation of new and refurbished retail stores. Our ongoing research aims to further assess the influence of isolated variables on retail EI and CI (like location, retail sub-type or building size) as well as the influence of isolated highperformance building solutions, like passive buildingenvelope measures, renewable-energy systems, smartlighting and other relevant building technologies.

Acknowledgements We would like to thank the reviewers for the important contribution in the improvement of this paper. Support from CERIS and Instituto Superior Técnico is also acknowledged.

Funding This work was supported by FCT — Fundação para a Ciência e Tecnologia [grant number PD/BD/127852/2016] under the Doctoral Program EcoCoRe-Eco-Construction and Rehabilitation. Support from CERIS and Instituto Superior Técnico is also acknowledged.

\section{Compliance with ethical standards}

Conflict of interest The authors declare that they have no conflict of interest.

\section{References}

Aeon (2015). Aeon environmental and social report. Retrieved October 21, 2016, from https://www.unglobalcompact. org/system/attachments/cop_2015/189821/original/AEON_ Environmental_and_Social_Report.pdf?1442556777

Aldi (2015). Aldi North Group Sustainability Report.

Borgstein, E. H., Lamberts, R., \& Hensen, J. L. M. (2016). Evaluating energy performance in non-domestic buildings: a review. Energy and Buildings, 128, 734-755. https://doi. org/10.1016/j.enbuild.2016.07.018.

Building Performance Institute Europe (2011). Europe's buildings under the microscope. Retrieved December 14, 2016, from b pie. EU/wp-content/uploads/2015/10/ HR_EU_B_under_microscope_study.Pdf.

Burck, J., Hagen, U., Höhne, N., Nascimento, L., \& Bals, C. (2019). Climate Change Performance Index 2020: results. Retrieved from www.germanwatch.orgwww.climatechange-performance-index.org

Carballo-Penela, A., \& Castromán-Diz, J. L. (2015). Environmental policies for sustainable development: an analysis of the drivers of proactive environmental strategies in the service sector. Business Strategy and the Environment, 24(8), 802-818. https://doi.org/10.1002/bse.1847.
Choi, D. Y., \& Gray, E. R. (2008). Socially responsible entrepreneurs: what do they do to create and build their companies? Business Horizons, 51(4), 341-352. https://doi.org/10.1016 j.bushor.2008.02.010.

Christina, S., Waterson, P., Dainty, A., \& Daniels, K. (2015). A socio-technical approach to improving retail energy efficiency behaviours. Applied Ergonomics, 47, 324-335. https://doi. org/10.1016/j.apergo.2014.08.003.

CommONEnergy Project (2013a). Re-conceptualize shopping malls from consumerism to energy conservation Deliverable 6.4 Energy savings result. Bolzano, Italy. Retrieved from http://www.commonenergyproject. eu/uploads/deliverable/file/35/WP6_D6.4_20171010_P04_ Energy_savings_results.pdf

CommONEnergy Project (2013b). Re-conceptualize shopping malls from consumerism to energy conservation - deliverable 6.5 IEQ results European Commission DG Research and Innovation CommONEnergy Re-conceptualize shopping malls from consumerism to energy conservation. Bolzano, Italy. Retrieved from http://www.commonenergyproject. eu/uploads/deliverable/file/36/WP6_D6.5_P01_20171129_ IEQ_results.pdf

de Fátima Castro, M., Mateus, R., Serôdio, F., \& Bragança, L. (2015). Development of benchmarks for operating costs and resources consumption to be used in healthcare building sustainability assessment methods. Sustainability, 7, 1322213248. https://doi.org/10.3390/su71013222.

Deloitte, \& Stores Media (2016). Global powers of retailing. Retrieved November 8, 2016, from https://www2.deloitte. com/content/dam/Deloitte/global/Documents/consumerindustrial-products/gx-cip-2017-global-powers-of-retailing. pdf

Dixon-O'Mara, C., \& Ryan, L. (2018). Energy efficiency in the food retail sector: barriers, drivers and acceptable policies. Energy Efficiency, 11(2), 445-464. https://doi.org/10.1007 /s12053-017-9577-5.

Edeka (2016). EDEKA energy efficiency building. Retrieved October 2, 2016, from http://iet.jrc.ec.europa. eu/energyefficiency/edeka-lebensmittelmarkt-rastatt-rheinau

ENDS Carbon - University of Edinburgh Business School (2009). UK supermarkets 2009 carbon benchmark report. Edinburgh.

European Parliament (2018). Directive 2018/844/EU amending directive $2010 / 31$ /EU on the energy performance of buildings and directive 2012/27/EU on energy efficiency. Retrieved from https://eur-lex.europa.eu/legalcontent/EN/TXT/PDF/?uri=CELEX:32018L0844\&from= EN.

European Parliament and European Council (2014). Regulation (EU) No 517/2014 of 16 April 2014 on fluorinated greenhouse gases and repealing regulation (EC) No. 842/2006. Retrieved May 6, 2019, from https://eur-lex.europa. eu/legal-content/EN/TXT/PDF/?uri=CELEX:32014R0517 $\&$ from $=\mathrm{EN}$.

European Union. (2016). Guidelines for the promotion of nearly zero-energy buildings and best practices to ensure that, by 2020, all new buildings are nearly zero-energy buildings Commission Recomendation (EU) 2016/1318 of 29 July 2016. Retrieved May 8, 2019, from http://www. sciencedirect.com/science/article/pii/S0306261911007811/.

Ferreira, A. S. (2018), "Combined carbon and energy intensity benchmarks for sustainable retail stores - CSR reports", 
Mendeley Data, v1. DOI:https://doi.org/10.17632 /gnygmhvv8d.1

Ferreira, A., Pinheiro, M. D., de Brito, J., \& Mateus, R. (2018a). Carbon $(\mathrm{CI})$ and energy intensity (EI) dataset for retail stores. Data in Brief, 21, 1329-1333. https://doi.org/10.1016/J. DIB.2018.10.080.

Ferreira, A., Pinheiro, M. D., de Brito, J., \& Mateus, R. (2018b). Combined carbon and energy intensity benchmarks for sustainable retail stores. Energy, 165. https://doi.org/10.1016/j. energy.2018.10.020.

Fieldson, R., \& Rai, D. (2009). An assessment of carbon emissions from retail fit-out in the United Kingdom. Journal of Retail \& Leisure Property, 8(4), 243-258. https://doi.org/10.1057 /rlp.2009.16.

Galvez-Martos, J.-L., Styles, D., \& Schoenberger, H. (2013). Identified best environmental management practices to improve the energy performance of the retail trade sector in Europe. Energy Policy, 63, 982-994. https://doi.org/10.1016 /j.enpol.2013.08.061.

Hahn, R., \& Luelfs, R. (2014). Legitimizing negative aspects in GRI-oriented sustainability reporting: a qualitative analysis of corporate disclosure strategies. Journal of Business Ethics, 123(3), 401-420. https://doi.org/10.1007/s10551-013-18014.

Jenkins, D. P. (2008). Using dynamic simulation to quantify the effect of carbon-saving measures for a UK supermarket. Journal of Building Performance Simulation, 1(4), 275288. https://doi.org/10.1080/19401490802566891.

Jiang, P., \& Keith Tovey, N. (2009). Opportunities for low carbon sustainability in large commercial buildings in China. Energy Policy, 37(11), 4949-4958. https://doi.org/10.1016/J. ENPOL.2009.06.059.

Kim, E.-H., \& Lyon, T. P. (2015). Greenwash vs. Brownwash: exaggeration and undue modesty in corporate sustainability disclosure. Organization Science, 26(3), 705-723. https://doi.org/10.1287/orsc.2014.0949.

Levin, K., \& Rich, D. (2017). Turning point: trends in countries' reaching peak greenhouse gas emissions over time. Washington DC. Retrieved from http://www.wri.org/.

Li, C., Hong, T., \& Yan, D. (2014). An insight into actual energy use and its drivers in high-performance buildings. Applied Energy, 131, 394-410. https://doi.org/10.1016/J. APENERGY.2014.06.032.

Lidl (2015). Rapports de durabilité. Retrieved September 11, 2018, from https://www.enrouteversdemain-lidl. be/introduction/rapports-de-durabilite/? g a $=2.152622129 .923055288 .1536665554$ 1973559847.1536665554.

Miles, M., \& Huberman, A. (1994). Qualitative data analysis (2nd ed.). Thousand Oaks: Sage Publications, Inc..

MSCI. (2017). Corporate Responsibility. Retrieved August 29, 2017, from https://www.msci.com/corporate-responsibility.

Natural Resources Canada. (2019). Electricity facts. Retrieved December 12, 2019, from https://www.nrcan.gc.ca/sciencedata/data-analysis/energy-data-analysis/energyfacts/electricity-facts/20068.

Ochieng, E. G., Jones, N., Price, A. D. F., Ruan, X., Egbu, C., \& Zuofa, T. (2014). Integration of energy efficient technologies in UK supermarkets. Energy Policy, 67, 388-393. https://doi. org/10.1016/j.enpol.2013.12.002.
Parguel, B., Benoit-Moreau, F., \& Larceneux, F. (2011). How sustainability ratings might deter 'Greenwashing': a closer look at ethical corporate communication. Journal of Business Ethics, 102(1), 15-28. https://doi.org/10.1007/s10551-0110901-2.

Patton, M. (2002). Qualitative research \& evaluation methods (3rd ed.). Thousand Oaks: Sage Publications, Inc..

Price, S. (2010). The potential of renewable energy as a riskmitigating factor. Journal of Retail \& Leisure Property, 9(2), 89-91. https://doi.org/10.1057/rlp.2010.4.

Rewe (2017). Rewe group sustainability report 2017 - GRI report. Retrieved October 19, 2018, from www.rewe-groupnachhaltigkeitsbericht.de/2017.

Richman, R., \& Simpson, R. (2016). Towards quantifying energy saving strategies in big-box retail stores: a case study in Ontario (Canada). Sustainable Cities and Society, 20, 6170. https://doi.org/10.1016/j.scs.2015.09.007.

Santos Ferreira, A. S. (2019). "Relating carbon and energy intensity of best performing retailers with policy, strategy and building practice", Mendeley Data, v1. https://doi. org/10.17632/82hv54pzrd.1

Schönberger, H., Martos, J. L. G., \& Styles, D. (2013). Best environmental management practice in the retail trade sector learning from frontrunners. https://doi.org/10.2791/1775.

Sebi, C., Nadel, S., Schlomann, B., \& Steinbach, J. (2019). Policy strategies for achieving large long-term savings from retrofitting existing buildings. Energy Efficiency, 12(1), 89105. https://doi.org/10.1007/s12053-018-9661-5.

Shi, Q., Yan, Y., Zuo, J., \& Yu, T. (2016). Objective conflicts in green buildings projects: a critical analysis. Building and Environment, 96, 107-117. https://doi.org/10.1016/j. buildenv.2015.11.016.

Spyrou, M. S., Shanks, K., Cook, M. J., Pitcher, J., \& Lee, R. (2014). An empirical study of electricity and gas demand drivers in large food retail buildings of a national organisation. Energy and Buildings, 68, 172-182. https://doi. org/10.1016/j.enbuild.2013.09.015.

Stapenhurst, T. (2009). The benchmarking book: a how-to-guide to best practice for managers and practitioners (1st ed.). Oxford: Elsevier.

Sullivan, R., \& Gouldson, A. (2013). Ten years of corporate action on climate change: what do we have to show for it? Energy Policy, 60, 733-740. https://doi.org/10.1016/j. enpol.2013.05.025.

Suri, H. (2011). Purposeful sampling in qualitative research synthesis. Qualitative Research Journal, 11(2), 63-75. https://doi.org/10.3316/QRJ1102063.

Tassou, S. A., Ge, Y., Hadawey, A., \& Marriott, D. (2011). Energy consumption and conservation in food retailing. Applied Thermal Engineering, 31(2-3), 147-156. https://doi. org/10.1016/j.applthermaleng.2010.08.023.

Testa, F., Iraldo, F., \& Daddi, T. (2017). The effectiveness of EMAS as a management tool: a key role for the internalization of environmental practices. Organization \& Environment, 31(1), 48-69. https://doi.org/10.1177 $/ 1086026616687609$.

The Conservation Foundation of Greater Toronto. (2006). Greening Retail: Engaging the retail sector in sustainability: Identifying the greening retail opportunity for canadian retailers. Retrieved from http://www.evanscompany. 
com/GreeningRetailReportPhase1.pdf. Accessed 14 Dec 2016.

Thompson, B. (2007). Green retail: Retailer strategies for surviving the sustainability storm. Journal of Retail \& Leisure Property, 6(4), 281-286. https://doi.org/10.1057/palgrave. rlp. 5100079 .

Tuczek, F., Castka, P., \& Wakolbinger, T. (2018). A review of management theories in the context of quality, environmental and social responsibility voluntary standards. Journal of Cleaner Production, 176, 399-416. https://doi.org/10.1016 /J.JCLEPRO.2017.12.161.

U.S. Department of Energy (2008). Building technologies office. Retrieved November 14, 2016, from http://energy. gov/eere/buildings/building-technologies-office.
United Nations (2015). Adoption of the Paris Agreement. Retrieved from https://unfccc.int/resource/docs/2015/cop21 /eng/109r01.pdf.

Wireman, T. (2004). In E. Genesis solutions (Ed.), Benchmarking Best Practices in Maintenance Management. New York: Industrial press.

WRI, \& WBCSD. (2016). Greenhouse gas protocol. Retrieved November 8, 2016, from http://www.ghgprotocol.org/.

Publisher's note Springer Nature remains neutral with regard to jurisdictional claims in published maps and institutional affiliations. 